\title{
Applicability of an Exponential Law in Creep of Metals
}

\author{
Manabu Tamura, Hisao Esaka and Kei Shinozuka \\ Department of Materials Science and Engineering, National Defense Academy, Yokosuka 239-8686, Japan
}

An exponential type creep equation has been developed for heat resistant steels by the authors. This equation was induced assuming both a thermally activated process for a mobile dislocation and rather high applied stress. The applicability of the new creep equation was examined for a pure iron, two kinds of Ni-base super alloys and an eutectic solder alloy in a $\mathrm{Pb}-\mathrm{Sn}$ system which were tested at relatively high temperatures and under very low stresses. All of the data obtained were completely explained by the new creep equation. The data for each alloy were classified into a few groups, where a deformation mechanism may be different with each other. The new creep equation is valid for stresses higher than the half value of the slope in a logarithm of time to rupture vs. linear stress diagram.

(Received August 23, 2002; Accepted November 25, 2002)

Keywords: creep equation, heat resistant steel, solder, super alloy, pure iron

\section{Introduction}

Creep rate or time to rupture of materials depends strongly on both temperature and stress, and many creep equations have been proposed. ${ }^{1-4)}$ A typical equation has been phenomenologically expressed as follows;

$$
\dot{\varepsilon}=\dot{\varepsilon}_{0} \sigma^{n} \exp (-Q / R T),
$$

where $\dot{\varepsilon}, \dot{\varepsilon}_{0}, \sigma, n, Q, R$ and $T$ are the steady state creep rate, a material constant, the uni-axial applied stress, the stress exponent, the apparent activation energy, the gas constant and the absolute temperature, respectively. The similar equation has been applicable to the time to rupture, because the Monkman-Grant relation ${ }^{5)}$ is valid for many materials. For many pure metals and soft materials it is known that when the stress is relatively low $n=3-5$, and the value of $Q$ is a little larger than that for self-diffusion, $Q_{\mathrm{d}}$. The values of the stress exponents have been semi-theoretically explained. ${ }^{6}$ However, for many practical materials, the values of $n$ and $Q$ in eq. (1) are much larger than $n=3-5$ and $Q_{\mathrm{d} \cdot}{ }^{2,4,7,8)}$

In order to compensate this inconsistency, a concept of effective stress, i.e. the applied stress minus the internal stress, $\sigma_{i}$, has been introduced. ${ }^{4,9,10)}$ Therefore, the creep equation has been modified as

$$
\dot{\varepsilon}=\dot{\varepsilon}_{0}\left(\sigma-\sigma_{\mathrm{i}}\right)^{n^{\prime}} \exp \left(-Q^{\prime} / R T\right) .
$$

Some researchers ${ }^{11-13)}$ reported that the modified stress exponent, $n^{\prime}$, and the modified apparent activation energy, $Q^{\prime}$, approached to the low values, respectively, which were explained by the classical creep theory. ${ }^{2,6)}$ However, as pointed by Feltham and Meakin ${ }^{14)}$ and/or Rösler and Artz, ${ }^{15}$ ) the physical meanings of the stress exponents, $n$ and $n^{\prime}$, and the apparent activation energies, $Q$ and $Q^{\prime}$, have not yet been clear. Moreover, though the some metallurgical explanations ${ }^{16,17)}$ were made concerning with the internal stresses, in general, the internal stress has not yet been correlated with microstructural parameters quantitatively.

On the other hand, theoretical creep equations of a sinh type have been also proposed on the bases of a thermally activated process for dislocation motion..$^{3,4,18-21)}$ The effective stress concept has also been discussed on the sinh equations. ${ }^{22,23)}$ However, physical meanings of the variables or the material constants of the creep equations, such as the activation energy, the activation volume and the internal stress, are not always clear and the relations between these variables or material constants and the microstructures have not yet been established satisfactorily. $3,4,18$ )

Under these circumstances, Tamura et $a l .{ }^{24)}$ have proposed a new creep equation of an exponential type for heat resistant steels on the assumption of a thermally activation process for slip motion of dislocations. The new equation has been proved to be applicable to the creep rupture data beyond 100 thousands hours ${ }^{24)}$ and the physical meanings of the material constants in the new equation have been discussed quantitatively. ${ }^{25)}$ The equivalent obstacle spacings which can be calculated using only the creep data are reported to be comparable to the microstructural parameters, such as interparticle distance, observed under a transmission electron microscope. ${ }^{25,26)}$

The applicability of the new equation has been established for only the practical heat resistant steels tested under relatively high stress levels. In this study, besides the data of the practical heat resistant steels, collecting creep data of some super alloys, a solder alloy and a pure iron which were obtained under low stresses and relatively high temperatures, the applicability of the new exponential creep equation has been studied extensively.

\section{Back Ground of the Exponential Law and Power Law}

In case of the uniform dislocation creep, the steady state creep rate is given by

$$
\dot{\varepsilon}=0.5 \rho b v,
$$

where $\rho, b, v$ are the mobile dislocation density, the length of Burgers vector and the average dislocation velocity, respectively. The coefficient of 0.5 in eq. (3) is a conversion factor of shear strain to normal strain. If the velocity of a dislocation is assumed to be controlled by a thermally activated process, $v$ is expressed by the following equation. 


$$
\begin{aligned}
v & =v_{0}\left\{\exp \left(-\frac{Q-\sigma V}{R T}\right)-\exp \left(-\frac{Q+\sigma V}{R T}\right)\right\} \\
& =v_{0} \exp \left(-\frac{Q}{R T}\right) \cdot 2 \sinh \left(\frac{\sigma V}{R T}\right),
\end{aligned}
$$

where $v_{0}$ is a material constant. $Q-\sigma V$ is the change in the Gibbs free energy for the forward motions of dislocations in the matrix of one mole and $Q+\sigma V$ is that for the backward motions and $-\sigma V$ corresponds to the potential drop of a loading system. ${ }^{27)}$ Since the Monkman-Grant relation, ${ }^{5)}$ eq. (5) where $C_{\mathrm{m}}$ is a constant, is hold between minimum creep rate and time to rupture, assuming that the steady state creep rate is nearly equal to the minimum creep rate and combining eqs. (3)-(5) the time to rupture, $t_{\mathrm{r}}$, is expressed as eq. (6).

$$
\begin{aligned}
\dot{\varepsilon} & =C_{\mathrm{m}} / t_{\mathrm{r}} \\
t_{\mathrm{r}} & =C_{\mathrm{m}} \cdot \frac{2}{\rho b v_{0}} \exp \left(\frac{Q}{R T}\right) / 2 \sinh \left(\frac{\sigma V}{R T}\right)
\end{aligned}
$$

Here, we define a new parameter, $X$, as

$$
X \equiv \frac{\sigma V}{R T} .
$$

The parameter, $X$, denotes what times the potential drop of a loading system during creep is larger than the energy of thermal fluctuation and we call $X$ temperature compensated stress, for simplicity.

When $X>1$, assuming that $\exp (-X)$ can be neglected as compared with $\exp (X)$, and defining $t_{\mathrm{r} 0}$ as eq. (8), the time to rupture, $t_{\mathrm{r}}$, is given by eq. (9) or $\left(9^{\prime}\right)$.

$$
\begin{aligned}
t_{\mathrm{r} 0} & \equiv \frac{2 C_{\mathrm{m}}}{\rho b v_{0}} \\
t_{\mathrm{r}} & =t_{\mathrm{r} 0} \exp \left(\frac{Q-\sigma V}{R T}\right) \\
\log t_{\mathrm{r}} & =\log t_{\mathrm{r} 0}+\frac{Q-\sigma V}{2.3 R T}
\end{aligned}
$$

This is the new equation proposed by the authors. ${ }^{24)}$ Figure 1 shows the stress vs. time to rupture diagram of

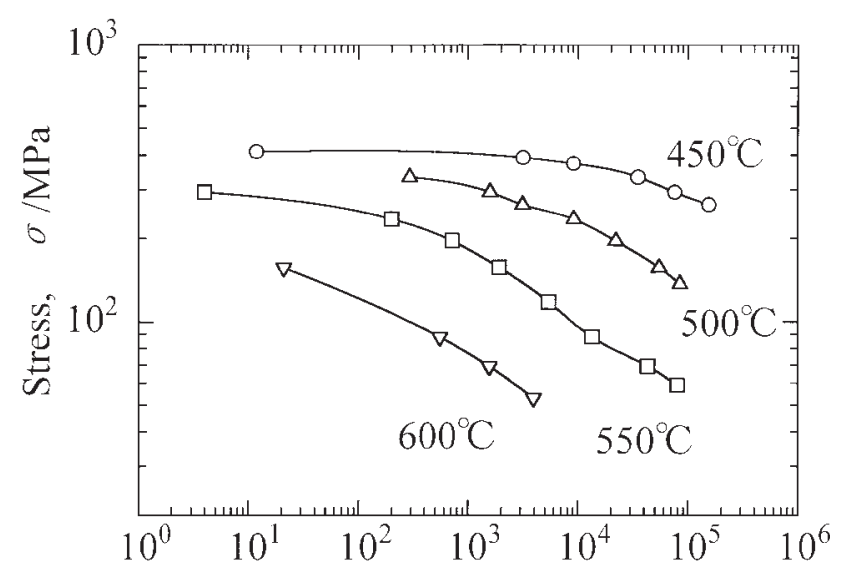

Time to rupture, $t r / \mathrm{h}$

Fig. 1 Logarithm of time to rupture vs. logarithm of stress diagram of $0.5 \% \mathrm{Cr}-0.5 \%$ Mo steel.

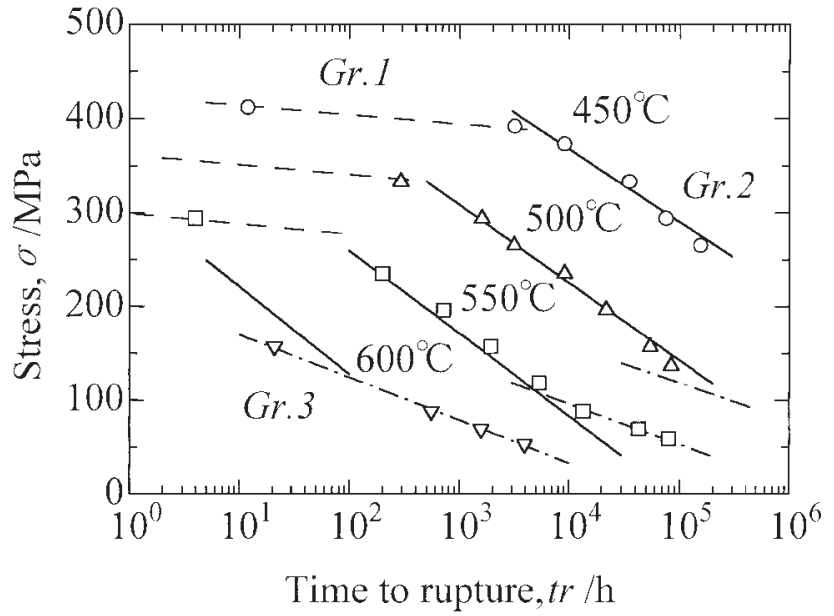

Fig. 2 Semi-logarithmic diagram of time to rupture and stress of $0.5 \% \mathrm{Cr}-$ $0.5 \%$ Mo steel.

$0.5 \% \mathrm{Cr}-0.5 \%$ Mo steel (STBA20 in JIS, Heat MFB) ${ }^{28)}$ where a log-log plot is adopted according to the conventional power law (hereinafter, $\%$ means mass $\%$ ). The data are fitting by a spooline for every temperature. A slope of the spooline, an absolute value of which corresponds to the stress exponent of eq. (1), varies complexly with the temperature and stress. Therefore, to predict the rupture stress at a longer time is very difficult. On the contrary, the new creep equation, eq. (9), requests that the linear stress should be plotted against the logarithm of the time to rupture. According to the theory, the data of $0.5 \% \mathrm{Cr}-0.5 \% \mathrm{Mo}$ steel are re-plotted as shown in Fig. 2. The data can be roughly classified into three groups fitted by almost parallel straight lines and the gradient for each group changes largely on the boundaries of about $150 \mathrm{MPa}$ or $1000 \mathrm{~h}$ at high stress as seen in the figure. This implies that after these boundaries the values of $Q, V$ and $t_{\mathrm{r} 0}$ change largely and, thus, a deformation mechanism and/or microstructure may change. These changes cannot be found out clearly through Fig. 1, i.e. a conventional log-log plot.

A parameter, $t_{\mathrm{r} 0}$, of eq. (9) is correlated with the wellknown constant of the Larson-Miller parameter, ${ }^{29)} C$, by eq. (10).

$$
C=-\log \left(t_{\mathrm{r} 0}\right)=\log \left(\frac{\rho b v_{0}}{2 C_{\mathrm{m}}}\right)
$$

Regression analyses were made on each data group according to eq. $\left(9^{\prime}\right)$ and the calculated values of $Q, V$ and $C$ are shown in Table 1.

Solving eq. (9) as $\sigma$, we obtain using eq. (10)

$$
\sigma=\frac{Q}{V}-\frac{2.3 R T}{V}\left(\log t_{\mathrm{r}}+C\right)
$$

According to eq. (11) we can easily draw the regression lines using the material constants. As shown in Fig. 2, the fitness of eq. (9) or (11) is excellent, and so the extrapolation of the data to a longer time is easy and accurate using the material constants listed in Table 1. Moreover, if the material constants, $Q, V$ and $C$, are given, the estimated relation between $\sigma$ and $t_{\mathrm{r}}$ at a temperature where creep tests were not conducted can be easily obtained. An example for Gr.3 of $0.5 \% \mathrm{Cr}-0.5 \% \mathrm{Mo}$ steel at $500^{\circ} \mathrm{C}$ is shown by a broken line in 
Table 1 Material constants of eq. (9).

\begin{tabular}{|c|c|c|c|c|}
\hline Alloy & Gr. & $\begin{array}{c}Q \\
\mathrm{~kJ} / \mathrm{mol}\end{array}$ & $\begin{array}{c}V \\
\mathrm{~cm}^{3} / \mathrm{mol}\end{array}$ & $C$ \\
\hline \multirow[t]{3}{*}{$0.5 \mathrm{Cr} 0.5 \mathrm{Mo}$} & Gr.1 & 1880 & 1419 & 92.51 \\
\hline & Gr.2 & 405 & 173 & 20.73 \\
\hline & Gr.3 & 414 & 365 & 20.06 \\
\hline \multirow[t]{4}{*}{$18 \mathrm{Cr} 8 \mathrm{Ni}$} & Gr.1 & 475 & 382 & 20.74 \\
\hline & Gr.2 & 440 & 648 & 17.14 \\
\hline & Gr.3 & 230 & 294 & 7.29 \\
\hline & Gr.4 & 310 & 1070 & 9.86 \\
\hline FETA1 & Gr.1 & 339 & 1839 & 15.28 \\
\hline \multirow[t]{2}{*}{ SSS113MA } & Gr.1 & 578 & 1378 & 18.94 \\
\hline & Gr.2 & 574 & 1691 & 18.20 \\
\hline \multirow[t]{2}{*}{$\mathrm{R} 4286$} & Gr.1 & 413 & 394 & 13.45 \\
\hline & Gr.2 & 881 & 1542 & 30.84 \\
\hline \multirow[t]{3}{*}{$\mathrm{SnPb}$} & Gr.1 & 67 & 1296 & 7.72 \\
\hline & Gr.2 & 75 & 1981 & 8.26 \\
\hline & Gr.3 & 168 & 17877 & 18.54 \\
\hline
\end{tabular}

Fig. 2.

The values of $Q$ for $0.5 \% \mathrm{Cr}-0.5 \% \mathrm{Mo}$ steel are considerably larger than the activation energy of self diffusion of the matrix and the physical meaning of $Q$ and $V$ are given in the literature. $^{25)}$ The values of $C$ of Grs.2 and 3 are near 20. However, the material constants of $\mathrm{Gr} .1$ of $0.5 \% \mathrm{Cr}-0.5 \% \mathrm{Mo}$ steel are less reliable because of the shortness of enough data number. As shown in eq. (10), $C$ is a function of mobile dislocation density and, therefore, should depend on the temperature and stress. However, empirically we have known that $C$ is roughly constant, i.e. 20 , over many creep data of a given material tested under various conditions.

In Fig. 2 the data were classified into three groups, for simplicity. However, the material constants of eq. (9) should be calculated using only three independent data with different stress and temperature. Therefore, $Q, V$ and $C$ can be calculated more precisely as a function of temperature, stress and time to rupture. Using these values the metallurgical parameters, such as the inter-particle distance, can be predicted like a function of continuous time, temperature and stress. ${ }^{25)}$

By the way, if $X \approx 0, \sinh X \approx X$ and, therefore, from eq. (6) we obtain

$$
t_{\mathrm{r}}=t_{\mathrm{r} 0} \frac{R T}{2 V} \sigma^{-1} \exp \left(\frac{Q}{R T}\right)
$$

This equation is phenomenologically equivalent to the Happer-Shepard-Dorn's equation ${ }^{19}$ ) which explains the creep rate of pure $\mathrm{Al}$ under extremely low stresses assuming uniform dislocation creep but not the Nabarro-Herring creep as a major deformation mechanism.

From eqs. (6)-(8), (10) the theoretical equation, eq. (6), can be rewritten as

$$
\ln t_{\mathrm{r}}+2.3 C-Q / R T=-\ln (2 \sinh X)
$$

When $X \gg 1$, the approximate equation, eq. (9), can be rewritten as

$$
\ln t_{\mathrm{r}}+2.3 C-Q / R T=-X .
$$

When $X \ll 1$, the approximate equation, eq. (12), can be rewritten as

$$
\ln t_{\mathrm{r}}+2.3 C-Q / R T=-\ln (2 X) .
$$

Figure 3 shows the theoretical relation between the parameter, $X$, and temperature compensated time to rupture, $\ln t_{\mathrm{r}}+2.3 C-Q / R T$. Time to rupture should be essentially expressed by eq. (6) or (13) for a dislocation creep if the Monkman-Grant relation is valid. However, it is clear from Fig. 3 that eq. (13) is suitably approximated by eq. (14) or (15) for $X>1$ or $X<1$, respectively. Equations (9) or (14) and (12) or (15) are simple and, therefore, suitable for practical use.

By the way, by expanding $\sinh X$ by a series, we obtain

$$
\sinh X=\sum_{n=1}^{\infty} \frac{X^{n}}{n !} \quad(n \text { : odd number })
$$

If $\sinh X$ could be represented by $X^{n} / n$ ! for the limited values of $X$, i.e.

$$
\sinh X \rightarrow \frac{X^{n}}{n !} .
$$

Combining eqs. (6) and (8), we obtain

$$
t_{\mathrm{r}}=t_{\mathrm{r} 0} n !\left(\frac{V}{R T}\right)^{n} \sigma^{-n} \exp \left(\frac{Q}{R T}\right)
$$

This equation is equivalent to the well-known power law type equation. The inducement of this equation was presented by Kimura, ${ }^{30)}$ but he did not claimed that eq. (18) is a theoretical one. If eq. (17) could be assumed, eq. (18) is rewritten as a next equation.

$$
\ln t_{\mathrm{r}}+2.3 C-Q / R T=-\ln \left[2\left(\frac{X^{n}}{n !}\right)\right]
$$

In Fig. 3 the relations of eq. (19) for $n=5$ and $n=10$ are

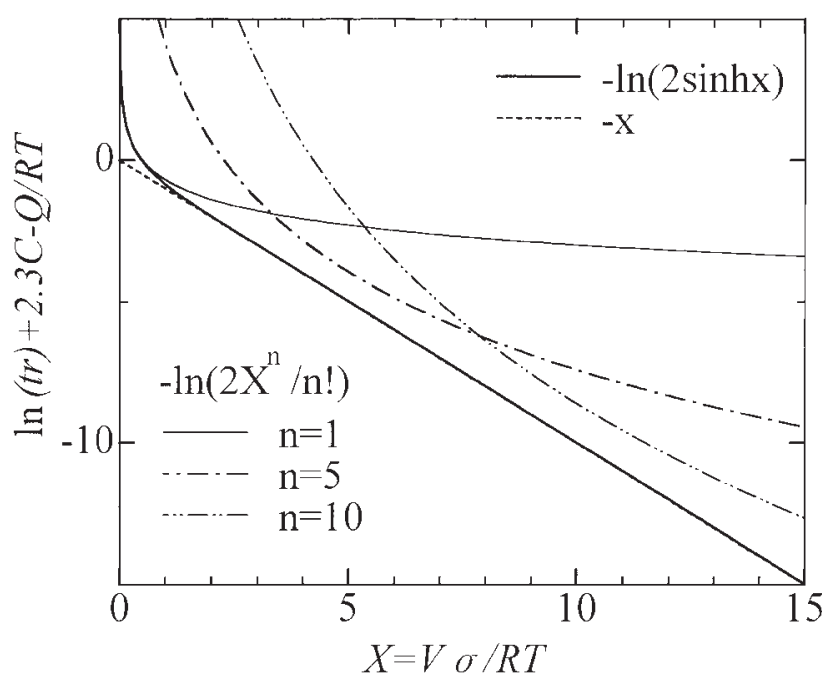

Fig. 3 Temperature compensated stress, $X$, vs. temperature compensated time to rupture, $\ln t_{\mathrm{r}}+2.3 C-Q / R T$, diagram. Bold real and dashed line correspond to theoretical eq. (12) and the proposed creep eq. (13), respectively. Fine three curves correspond to eq. (18) for $n=1,5$ and 10, respectively. 
drawn. It is seen from Fig. 3 that the value of the right hand side of eq. (19) is always larger than the theoretical value of eq. (13) for a given value of $X$ and is approaching to the theoretical line within a factor of 2 for the limited values of $X$. In other word, in order to approach the right hand side of eq. (19) closely to the theoretical value, i.e. $-\ln (2 \sinh X)$ over a wide range of $X$, the value of $n$ should be changing according to the value of $X$, i.e. stress and temperature. On the contrary, it is clear from Fig. 3 that if the value of $n$ is constant, the power low equation is not valid for a wide range of $X$ as compared with the exponential low. Setting $n=1$ in eq. (19), we obtain the same equation with eq. (15). This means that the power law equation is theoretically significant only when $n=1$.

The new creep equation eq. (9) or (14) is exactly valid for $X>1$. Therefore, it becomes a problem to show the reasonableness of the assumption of $X>1$.

\section{Value of $X$ for Some Materials}

\subsection{Heat resistant steel for power boilers}

It is easy to plot creep data on an $X$ vs. temperature compensated time to rupture diagram like Fig. 3 if the material constants, $Q, V, C$ are known as shown in Table 1 . The results for the $0.5 \% \mathrm{Cr}-0.5 \% \mathrm{Mo}$ steel are shown in Fig. 4. It is seen from Fig. 4 that all of the data for Gr.2 and 3 lie in a range of $X>2$ and are very closely on the theoretical line. In the figure, the data for Gr.1 are omitted for simplicity, because $X$ is ranging from 60 to 100 . However, the data for Gr.1 are on the theoretical line like Grs.2 and 3.

There have been many methods describing creep stress as a function of temperature compensated strain rate or time to rupture, i.e. the Zener-Hollomon parameter, ${ }^{19,23,31)}$ the OrrSherby-Dorn parameter, ${ }^{32)}$ the Larson-Miller parameter, ${ }^{29)}$ etc., ${ }^{2,3)}$ but the master curves are still curved and some extra parameters are needed for describing the master curves, though the unknown constant in the parameter is only one, like the Larson-Miller parameter, $P=T\left(\log t_{\mathrm{r}}+C\right)$. In order to illustrate Fig. 4 we need three kinds of parameters for each data group or 6 materials constants, i.e. $Q_{2}, V_{2}, C_{2}$ and $Q_{3}, V_{3}$,

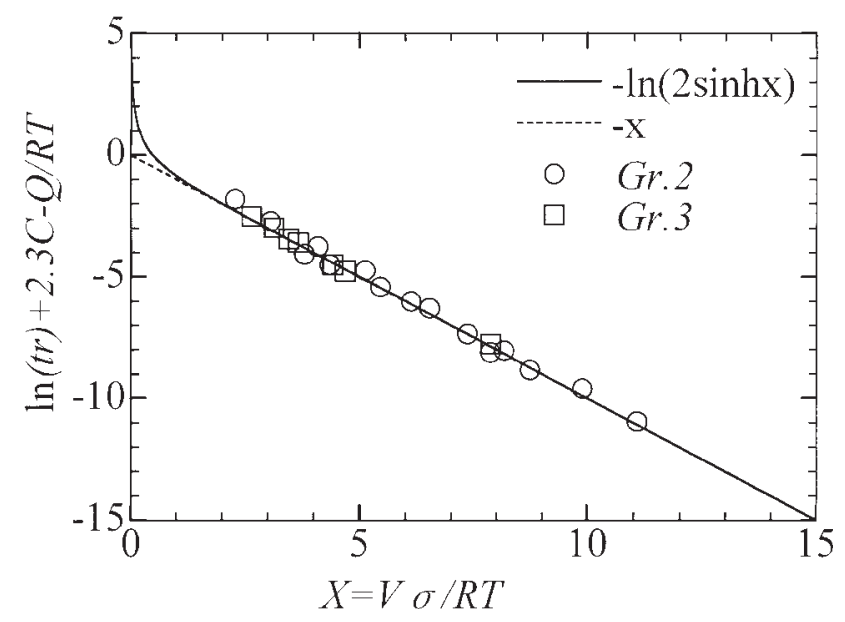

Fig. 4 Temperature compensated stress, $X$, vs. temperature compensated time to rupture, $\ln t_{\mathrm{r}}+2.3 C-Q / R T$ for $\mathrm{Grs} .2$ and 3 of $0.5 \% \mathrm{Cr}-0.5 \% \mathrm{Mo}$ steel.

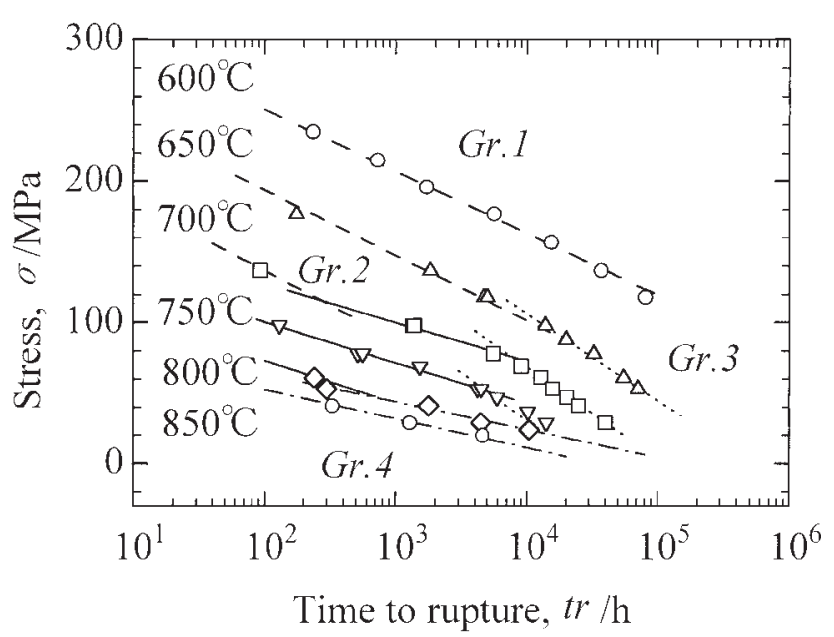

Fig. 5 Semi-logarithmic diagram of time to rupture and stress of $18 \% \mathrm{Cr}-$ $8 \% \mathrm{Ni}$ steel.

$C_{3}$. However, these material constants can be easily and steadily calculated as mentioned above and the master curve is always theoretically linear line given by eq. (14).

Figure 5 shows a stress vs. time to rupture diagram of $18 \% \mathrm{Cr}-8 \% \mathrm{Ni}$ steel (SUS304HTB in JIS Heat ABA) ${ }^{33}$ ) The rupture data can be classified into 4 groups. The material constants of eq. (9) are listed in Table 1. The values of materials constants for Grs. 1 and 2 are common in most of the practical heat resistant steels. ${ }^{24)}$ The values of $C$ and $Q$ for Gr.4 are rather small and the value of $V$ for Gr.4 is large as compared with those for Grs. 1 and 2. This trend is general for many heat resistant steels tested at high temperature. ${ }^{24,25)}$ On the contrary, the values of $Q, V, C$ for Gr.3 are small as compared with those of the other groups. Under the test conditions for Gr.3 sigma phase is formed on the grain boundaries, and so, a lot of cavities are formed near the sigma phase particles, and as a result specimens are ruptured after small tensile elongation. ${ }^{24)}$ The non-uniform deformation like this is out of the scope of the present theory, i.e. eq. (9). Figure 6 shows an $X$ vs. $\ln t_{\mathrm{r}}+2.3 C-Q / R T$ diagram of the $18 \% \mathrm{Cr}-8 \% \mathrm{Ni}$ steel. From the figure it is seen that all of the data lie in a narrow band near the theoretical line, i.e. eq. (13).

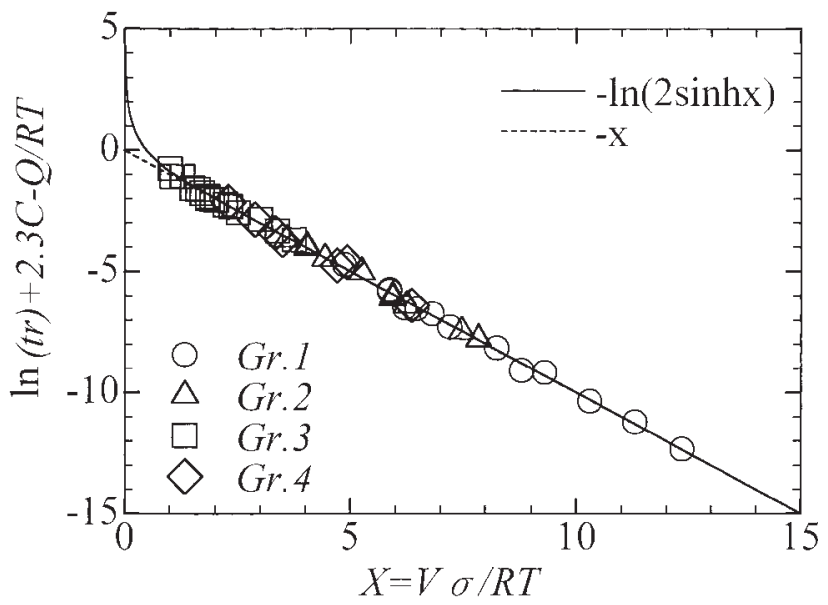

Fig. 6 Temperature compensated stress, $X$, vs. temperature compensated time to rupture, $\ln t_{\mathrm{r}}+2.3 C-Q / R T$ of $18 \% \mathrm{Cr}-8 \% \mathrm{Ni}$ steel. 
The values of $X$ for Grs.1, 2 and 4 are larger than 2 and the minimum value of $X$ is not realized at high temperatures, i.e. Gr.4, but the minimum occurs for Gr.3, where the nonuniform deformation due to the precipitation of $\sigma$ phase on the grain boundaries controls the rupture life.

\subsection{Pure iron}

Figure 7 shows a stress vs. time to rupture diagram of pure iron. The chemical composition of the pure iron is $0.0031 \% \mathrm{C}-0.0019 \% \mathrm{~N}-0.02 \% \mathrm{Al}-\mathrm{Fe}$ and the details of a manufacturing procedure is shown in the literature. ${ }^{26)}$ Linear relations are confirmed in a $\sigma$ vs. $\log t_{\mathrm{r}}$ diagram, though the test durations are limited in order to prevent the effect of nitrization during creep test in air. The values of the material constants are listed in Table 1. That the apparent activation energy is roughly equal to the activation energy of selfdiffusion and that the activation volume increases are general characteristics of soft materials tested at high temperatures. $^{24,34)}$ Figure 8 shows an $X$ vs. $\ln t_{\mathrm{r}}+2.3 C-Q / R T$ diagram of the pure iron. The values of $X$ are larger than 3 , though the test durations are limited. The value of $X$ is

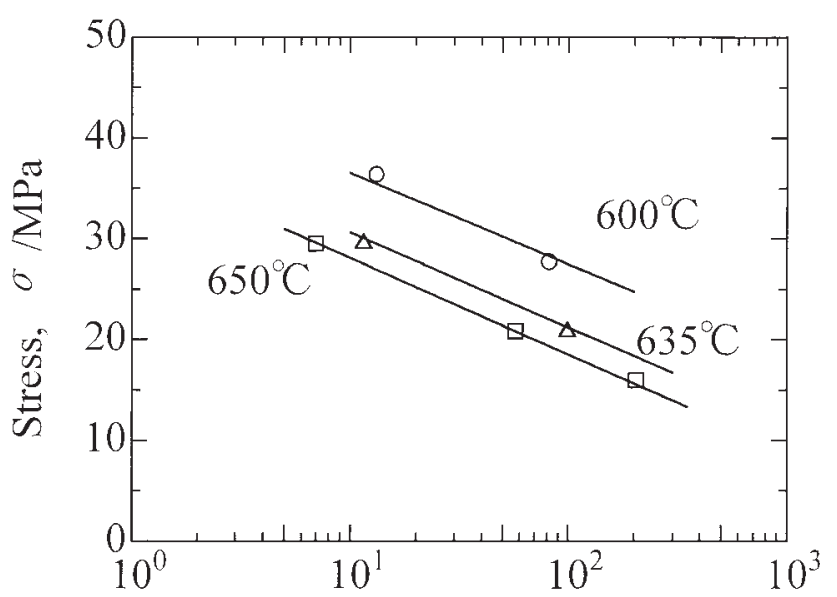

Time to rupture, $\operatorname{tr} / \mathrm{h}$

Fig. 7 Semi-logarithmic diagram of time to rupture and stress of pure iron.

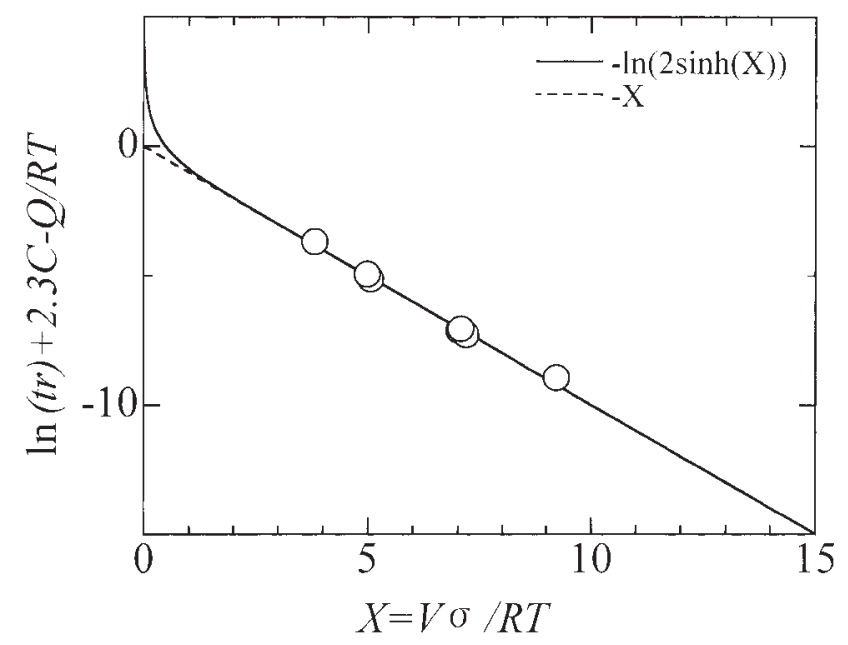

Fig. 8 Temperature compensated stress, $X$, vs. temperature compensated time to rupture, $\ln t_{\mathrm{r}}+2.3 C-Q / R T$ of pure iron. decreasing when the stress is decreasing, if the same deformation mechanism is operating and then the linear relation of eq. (14) will break down when $X<1$. However, in order to confirm this break down we need several thousands hours at least and also we needs setting a vacuum chamber on a creep tester to prevent the nitrization. Therefore, these problems should be solved in future.

\subsection{Super alloy}

There are many creep data of high strength super alloys for use in jet engines. However, what we should discuss in this paper is whether the linear relation of eq. (9) or (14) breaks down or not for a low value of $X$, i.e. low stress and high temperature test. In this sense, a stress vs. time to rupture diagram of SSS113MA is shown in Fig. 9. The alloy was developed for use in a steam generator of nuclear steel making processes. ${ }^{34)}$ The chemical composition of SSS113MA is $0.035 \% \mathrm{C}-0.04 \% \mathrm{Si}-22.64 \% \mathrm{Cr}-17.69 \% \mathrm{~W}-$ $0.47 \mathrm{Ti}-0.032 \% \mathrm{Zr}-0.0007 \% \mathrm{~N}-0.16 \% \mathrm{Fe}-\mathrm{Ni}$. The specimens were taken from a seamless tube and the details of the manufacturing procedures are shown in the literature and the creep tests were conducted in air. ${ }^{35,36)}$ The creep data were classified into 2 groups and the material constants were listed in Table 1. The high values of $V$ is a characteristic feature for high temperature creep and the high value of $Q$ is a characteristic feature of high strength materials. ${ }^{24,25)}$ Figure 10 shows an $X$ vs. $\ln t_{\mathrm{r}}+2.3 C-Q / R T$ diagram of SSS113MA. The values of $X$ for Gr.2 are ranging in a low value of $X$. However, the minimum value of $X$ is larger than 2 even for the creep test at $1050^{\circ} \mathrm{C}$ beyond several thousands hours. Therefore, the exponential law represented by eqs. (9) and (14) is valid for not only the heat resistant steels but also the super alloys tested even at very high temperatures. Equation (9) is induced assuming the uniform deformation due to the dislocation creep, which excludes the local deformation as observed in the $18 \% \mathrm{Cr}-8 \% \mathrm{Ni}$ steel, i.e. $\mathrm{Gr} .3$ of Fig. 5. It is well known that at high temperatures grain boundary sliding may take place. Concerning to this point Tamura et al. $^{37)}$ reported that the grain boundary sliding is not a rate controlling mechanism in SSS113MA.

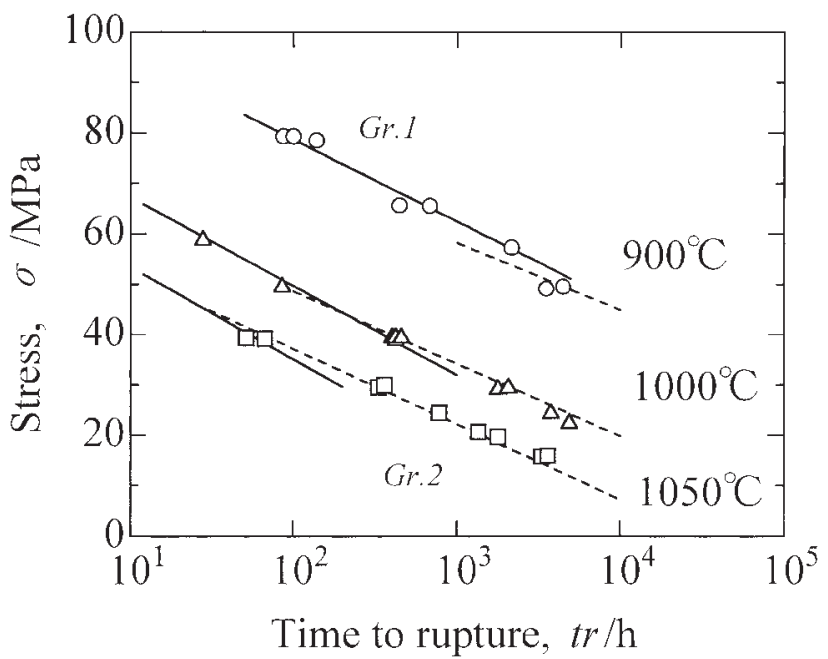

Fig. 9 Semi-logarithmic diagram of time to rupture and stress of Ni-base super alloy, SSS113MA. 


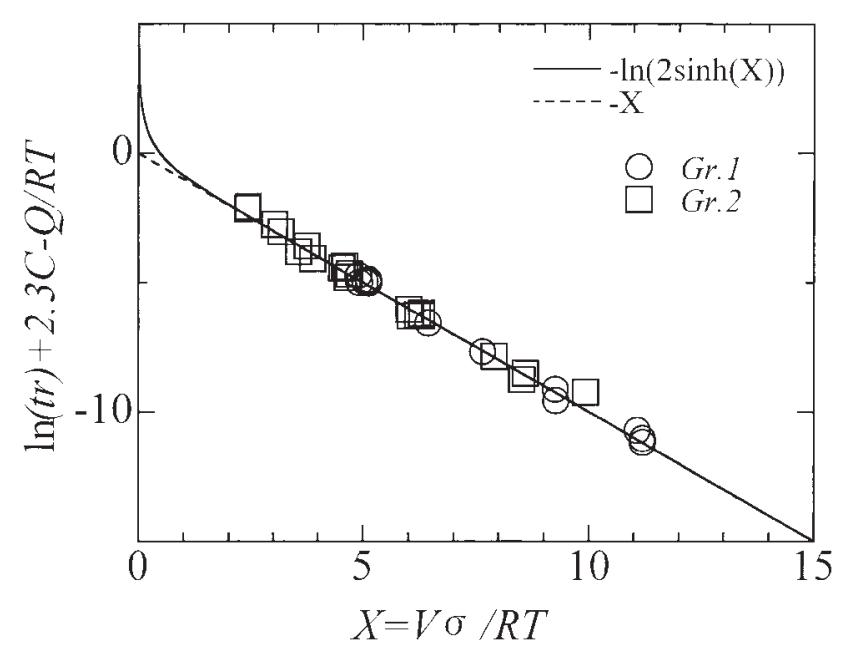

Fig. 10 Temperature compensated stress, $X$, vs. temperature compensated time to rupture, $\ln t_{\mathrm{r}}+2.3 C-Q / R T$ of Ni-base super alloy, SSS113MA.

The national project on the nuclear steel making had developed several superior super alloys. ${ }^{34)}$ Among these alloys, R4286 is another typical super alloy, which is strengthened by $\gamma^{\prime}$ phase. The chemical composition is $0.049 \% \mathrm{C}-0.06 \% \mathrm{Si}-18.89 \% \mathrm{Cr}-10.65 \% \mathrm{Co}-3.98 \% \mathrm{Mo}-5.80 \mathrm{~W}-$ $2.13 \% \mathrm{Al}-2.41 \% \mathrm{Ti}-0.0036 \% \mathrm{~B}-0.054 \% \mathrm{Zr}-0.31 \% \mathrm{Fe}-\mathrm{Ni}{ }^{38)}$ The specimens were taken from a bar and the creep tests were conducted in air and the details of the manufacturing procedures are shown in the literature. ${ }^{36)}$ Figure 11 shows a stress vs. time to rupture diagram of R4286. ${ }^{36,38)}$ The rupture strengths of R4286 at $1000^{\circ} \mathrm{C}$ are comparable with those of SSS113MA, however the rupture strengths of R4286 at $900^{\circ} \mathrm{C}$ are much higher than those of SSS113MA, which are caused by the precipitation of $\gamma^{\prime}$ phase. The creep data were classified into 2 groups, though the data are limited and the material constants were listed in Table 1 . The reliability of the material constants is not so high as compared with the other materials. The high values of $V$ for Gr.2 is a characteristic feature for high temperature creep and the high value of $Q$ is a characteristic feature of high strength

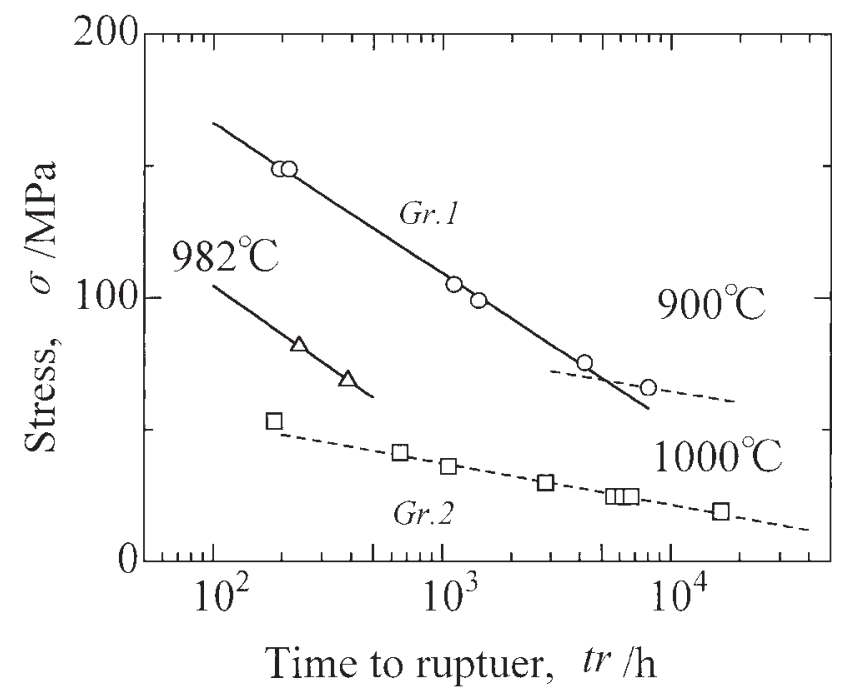

Fig. 11 Semi-logarithmic diagram of time to rupture and stress of Ni-base super alloy, R4286.

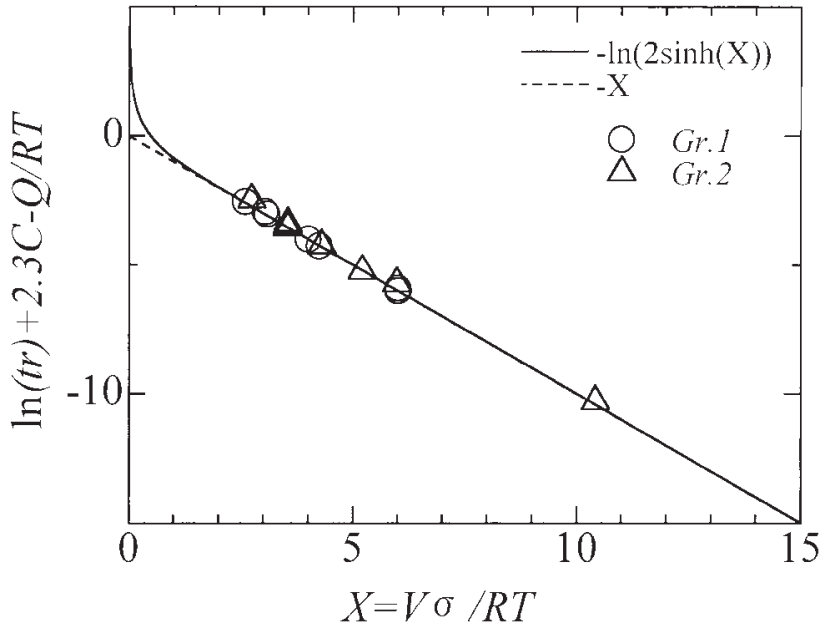

Fig. 12 Temperature compensated stress, $X$, vs. temperature compensated time to rupture, $\ln t_{\mathrm{r}}+2.3 C-Q / R T$ of Ni-base super alloy, R4286.

materials. $^{24,25)}$ Figure 12 shows an $X$ vs. $\ln t_{\mathrm{r}}+2.3 C-$ $Q / R T$ diagram of $\mathrm{R} 4286$. It is seen from the figure that the minimum value of $X$ is larger than 2 .

\subsection{Solder alloy}

In the previous section it is shown that the exponential law is valid even for the super alloys tested at very high temperatures. The normalized testing temperature, $T / T_{\mathrm{m}}$, of the super alloys is around $70 \%$ and enough high as compared with those of the heat resistant steels for power boilers, i.e. $60 \%$ at most where $T_{\mathrm{m}}$ is the melting point in Kelvin. Another typical practical material with high $T / T_{\mathrm{m}}$ is solder alloy, i.e. about $70 \%$.

Figure 13 shows a stress vs. time to rupture diagram of a eutectic alloy in a $\mathrm{Pb}-\mathrm{Sn}$ system. The chemical composition of the solder is $37.45 \% \mathrm{~Pb}-\mathrm{Sn}$. The alloy is melted at $300^{\circ} \mathrm{C}$ and cast in a steel crucible of 15 inner diameter and 120 depth in $\mathrm{mm}$. The ingots were pre-heated at $80^{\circ} \mathrm{C}$ for $20 \mathrm{~h}$ for the purpose of normalization and the creep specimens were machined with the gauge portion $\phi$ of 9 and $\ell 45 \mathrm{~mm}$ and the creep rupture tests were conducted at room temperature to

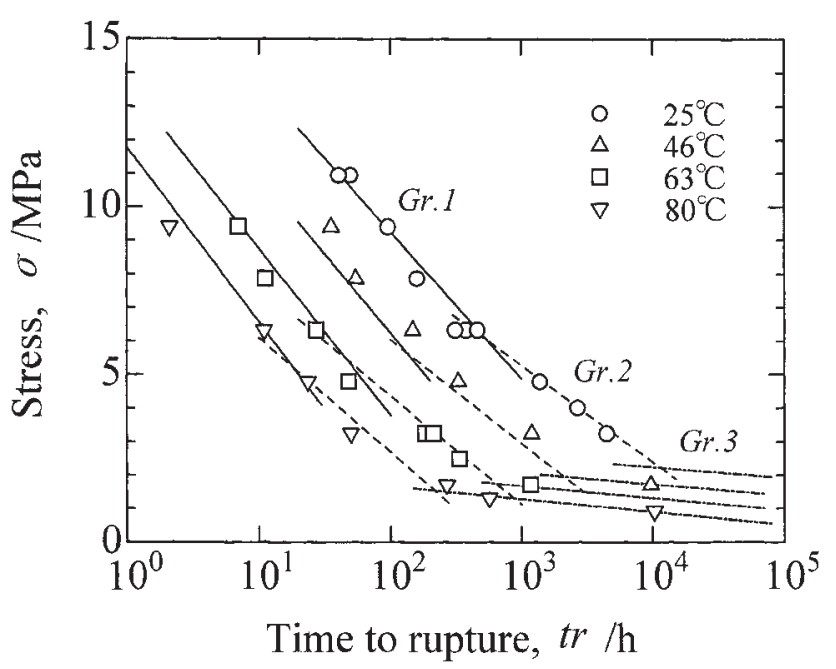

Fig. 13 Semi-logarithmic diagram of time to rupture and stress of a $\mathrm{Pb}-\mathrm{Sn}$ eutectic solder alloy. 
$80^{\circ} \mathrm{C}$. The creep data can be classified into three groups as shown in the figure. The material constants calculated using eq. (9) are listed in Table 1. High values of $V$ are a characteristic feature of the creep tests at high temperatures. The values of $Q$ for Grs. 1 and 2 are about the half values of the activation energy of self diffusion of $\mathrm{Pb}$ or $\mathrm{Sn}^{43)}$ and are comparable to the activation energy of grain boundary diffusion of $\mathrm{Pb}$ or $\mathrm{Sn}^{44)}$ On the other hand, the value of $Q$ for $\mathrm{Gr} .3$ is comparable to the activation energy of self diffusion of the constituent elements. Takada et al. reported the results of creep rupture test of $37 \% \mathrm{~Pb}-\mathrm{Sn}$ solder alloy. ${ }^{45)}$ Their data were re-analyzed using eq. (9) and $57.4 \mathrm{~kJ} / \mathrm{mol}$ was obtained as the apparent activation energy. The values of $Q$ for some lead free solder alloys were also determined using a conventional creep equation like eq. (1) and the value is ranging from 52 to $115 \mathrm{~kJ} / \mathrm{mol}^{46,47)}$ Therefore, the observed value of $Q$ for the solder alloy is essentially same with the other researchers and, thus, the creep data shown in Fig. 13 are reliable.

The low value of the activation energy suggests that the creep phenomenon for Grs. 1 and 2 is mainly controlled by boundary diffusion between the eutectic phases in the fine eutectic structure. And the high value of the activation energy for Gr.3 suggests that under lower stresses, i.e. after longer times, the fine eutectic structure may become coarse and volume diffusion mainly controls the creep rate for Gr.3. In order to confirm this explanation the metallurgical observation should be needed. However, the long-term tests are now under loading and the metallurgical analyses have not been completed.

The exponential creep equation of eq. (9) has been introduced on the assumption of uniform dislocation creep. However, this may not be always a necessary condition. The reason is that eq. (9) is valid even when the non-uniform deformation near the boundaries, i.e. Grs. 1 and 2 of the solder alloy (Fig. 13), determines the rupture life, if a thermal activated process controls the rupture life.

Figure 14 shows an $X$ vs. $\ln t_{\mathrm{r}}+2.3 C-Q / R T$ diagram of the $\mathrm{Pb}-\mathrm{Sn}$ solder. The minimum value of $X$ occurs at $80^{\circ} \mathrm{C}$ and $1.7 \mathrm{MPa}$, Gr.2, and the relation of $X>1$ is still hold.

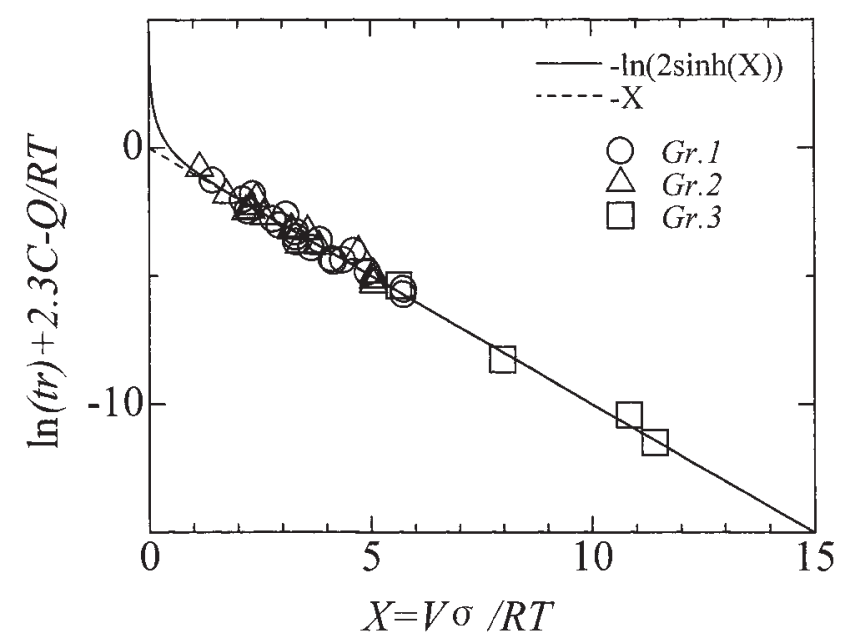

Fig. 14 Temperature compensated stress, $X$, vs. temperature compensated time to rupture, $\ln t_{\mathrm{r}}+2.3 C-Q / R T$ of a $\mathrm{Pb}-\mathrm{Sn}$ eutectic solder alloy.

\section{Discussion}

\subsection{Materials to which the exponential law can be applicable}

From the above discussion it is clear that the relation of $X>1$ is hold and, therefore, the exponential law should be valid for not only the practical heat resistant steels but also both the super alloys and the solder alloy tested under a wide range of test conditions.

The exponential law is valid on the following assumptions; I) the creep rate is controlled by the dislocation creep, II) the velocity of dislocations is controlled by a thermally activated process, III) the Monkman-Grant relation ${ }^{5)}$ is established and IV) the material constants, $Q, V, C$, are constant. ${ }^{27)}$ Physical meanings of the material constants, $Q, V, C$, can be explained, if the above assumptions are satisfied. ${ }^{28)}$ The last assumption can be satisfied, if the test conditions are in a narrow range. The 3rd assumption may break down when rupture elongation is small. In such a case, an exponential creep law concerning steady state creep rate which is similar with eq. (9) should be established. Therefore, the steady state creep rate for a given temperature and stress can be estimated, though the reliable open literature on steady state creep for these material is limited. Among the assumptions the 1st assumption is the most important. However, the exponential law is still hold within limited test conditions for the materials of the eutectic solder alloy as shown in Fig. 13 and the $18 \% \mathrm{Cr}-8 \% \mathrm{Ni}$ stainless steel of which rupture life is controlled by intra-granular fracture due to the brain boundary precipitation of sigma phase. ${ }^{27)}$ The calculated values of $Q$ for these alloys are, in general, smaller than the values of self diffusion of the matrix and, in other word, in such cases it is guessed that non-uniform deformation such as crack propagation along grain boundaries may take place.

\subsection{Prediction of rupture life at a longer time}

The creep equation can provide us I) proper interpretation for creep deformation and II) the prediction of rupture life at a longer time. Concerning the 2nd purpose many researchers have proposed some creep equations and the evaluations for these creep equation have been made. ${ }^{1-26)}$ It is well known that the extrapolated rupture strength by the Larson-Miller method is higher than the experimental values. In order to improve this fault many parametric methods have been developed $^{32,36)}$ and recently the accuracy of the prediction has been improved by analyzing creep curves ${ }^{48)}$ However, physical and/or metallurgical meanings of many adjustable parameters adopted have not been explained. Therefore, we cannot ascertain whether the values of the parameters which are optimized using short time data can be acceptable at a long time or not. Namely, many parametric creep equations can be certainly applicable for the interpolation of rupture life, but careful attention should be needed for the extrapolation of rupture life.

On the other hand, the proposed exponential law is a theoretical one and, therefore, eq. (9) can be applicable for the extrapolation of rupture life, if the above assumptions are satisfied and the material constants, $Q, V, C$, are metallurgically reasonable in an aiming test condition. 


\subsection{Applicable limit of the exponential law}

In the linear stress vs. logarithm of time to rupture diagrams as shown in Figs. 2, 5, 7, 9, 11 and 13 there are many folding points on the regression lines at a constant temperature. Deformation mechanism may change around these folding points, where the material constants change as shown in Table 1. At the folding points the regression lines are concave upward, then the rupture life become longer after the folding points. On the other hand, time to rupture observed should become longer at a lower stress as expected from the high stress data, according to the theoretical equation, i.e. eq. (6). In order to distinguish these two effects, an $X$ vs. $\ln t_{\mathrm{r}}+2.3 C-Q / R T$ diagram of the $\mathrm{Pb}-\mathrm{Sn}$ solder is re-plotted in Fig. 15. The black dots in the figure are the data for Gr.1. If the creep tests are conducted under much lower stresses and the same deformation mechanism is operating, the data points obtained should be plotted along the real line, i.e. the $\sinh$ law. The values of $\ln t_{\mathrm{r}}+2.3 C-$ $Q / R T$ for Grs.2 and 3 are calculated using the material constants of Gr.1 and the results are plotted in the figure by open circles. However, as shown in the figure, the calculated values shown by the open circles do not follow the sinh law. Therefore, it is clear that deformation mechanisms for Grs. 2 and 3 should be differ from that of Gr.1, because the rupture lives presented by the open circles are longer than those calculated from the theoretical one, i.e. the real line in Fig. 15.

Since the exponential law represented by eq. (9) is an approximate equation of the theoretical equation of eq. (6), there should be an application limit of eq. (9). Differentiating partially eq. (11) by $\log t_{\mathrm{r}}$, we obtain using eq. (7)

$$
\frac{\partial \sigma}{\partial \log t_{\mathrm{r}}}=-\frac{2.3 \sigma}{X}
$$

If we assume that the approximation breaks down when $X=1$, we obtain

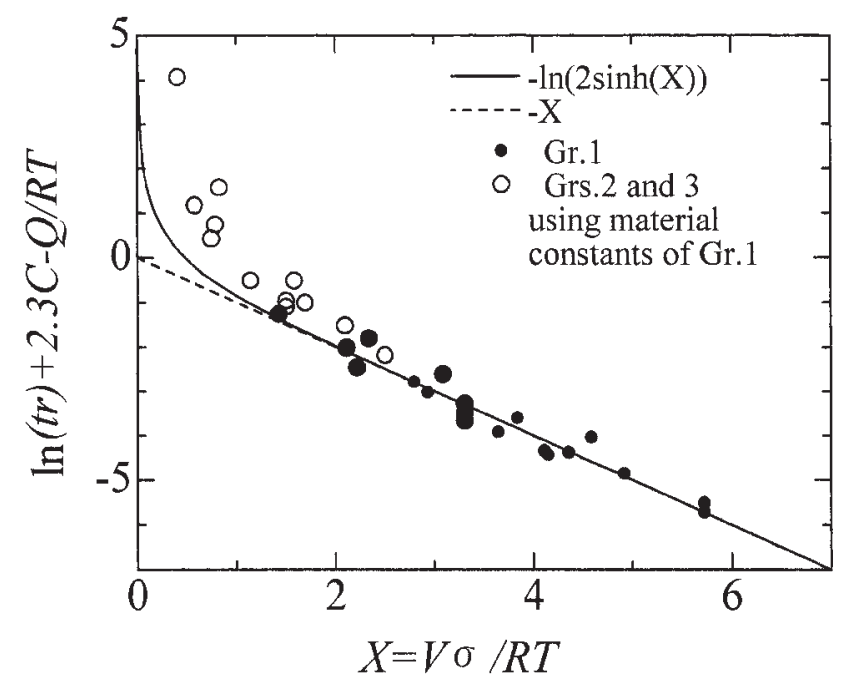

Fig. 15 Temperature normalized stress, $X$, vs. temperature compensated time to rupture, $\ln t_{\mathrm{r}}+2.3 C-Q / R T$ of a $\mathrm{Pb}-\mathrm{Sn}$ eutectic solder alloy. All data points for Grs. 2 and 3 are calculated using the material constants for Gr.1 and are plotted by open circles.

$$
\frac{\partial \sigma}{\partial \log t_{\mathrm{r}}}=-2.3 \sigma
$$

or,

$$
\sigma=0.43\left|\frac{\partial \sigma}{\partial \log t_{\mathrm{r}}}\right| .
$$

The absolute value, $\left|\frac{\partial \sigma}{\partial \log t_{\mathrm{r}}}\right|$, means the slope of a regression line in a $\sigma$ vs. $\log t_{\mathrm{r}}$ diagram. Therefore, the exponential law is judged to be valid roughly for a stress higher than a half value of change in stress, $\Delta \sigma$, for change of one digit in time to rupture, $\Delta \log t_{\mathrm{r}}=1$. However, as shown in Figs. 4, 6, 8, 10,12 and 14, temperature compensated stresses, $X$, are always larger than one and, therefore, the exponential law is applicable to many kinds of alloys tested under a widely ranged conditions independent of the difference in a deformation mechanism.

\section{Conclusion}

The creep equation of an exponential law type which has been developed for some heat resistant steels by the authors is applied to a pure iron (tested at $600-650^{\circ} \mathrm{C}$ ), the super alloys of the chemical compositions: $0.035 \% \mathrm{C}-0.04 \% \mathrm{Si}-$ $22.64 \% \mathrm{Cr}-17.69 \% \mathrm{~W}-0.47 \mathrm{Ti}-0.032 \% \mathrm{Zr}-0.0007 \% \mathrm{~N}-$

$0.16 \% \mathrm{Fe}-\mathrm{Ni}$ (tested at $900-1050$ ) and $0.049 \% \mathrm{C}-0.06 \% \mathrm{Si}-$ $18.89 \% \mathrm{Cr}-10.65 \% \mathrm{Co}-3.98 \% \mathrm{Mo}-5.80 \% \mathrm{~W}-2.13 \% \mathrm{Al}-$

$2.41 \% \mathrm{Ti}-0.0036 \% \mathrm{~B}-0.054 \% \mathrm{Zr}-0.31 \% \mathrm{Fe}-\mathrm{Ni}$ (tested at 900 $1000^{\circ} \mathrm{C}$ ) and a eutectic solder alloy of $\mathrm{Pb}-\mathrm{Sn}$ system (tested at room temperature to $80^{\circ} \mathrm{C}$ ). Following conclusions are obtained.

(1) The exponential law is valid not only for heat resistant steels but also for the pure iron, the super alloys and the eutectic $\mathrm{Pb}-\mathrm{Sn}$ solder which were tested at relatively high temperatures and under low stresses.

(2) The creep data can be in general, classified into a few groups, where a deformation mechanism may be different with each other.

(3) The exponential law is valid for a stress roughly higher than the half value of a slope in a linear stress vs. logarithm of time to rupture diagram.

\section{REFERENCES}

1) F. K. G. Odqvist and J. Hult: Kriechfestigkeit Metallischer Werkstoffe, Springer-Verlag Berlin, (1962), translated by S. Murakami, (Baihukan, Tokyo, 1967) pp. 23-44.

2) O. D. Sherby and P. M. Burke: Mechanical Behavior of Crystalline Solid at Elevated Temperature, Progress in Materials Science, 13 (Pregamon Press, 1968) pp. 340-347.

3) S. Takeuchi and A. S. Argon: J. Mater. Sci. 11 (1976) 1542-1566.

4) W. Blum: High-Temperature Deformation and Creep of Crystalline Solids, Materials Science and Technology, VCH, Weinheim, ed. by R. W. Cahn et al., 6 (1993) 360-405.

5) F. C. Monkman and N. J. Grant: Proc. ASTM 56 (1956) 593-620.

6) J. Weertman: J. Appl. Phys. 28 (1957) 362-364.

7) K. Maruyama and H. Nakashima: Koonkyoudo no Zairyoukagaku, (Uchida Rokakuho Pub., Tokyo, 1997) pp. 20-22.

8) K. Maruyama and H. Nakashima: Koonkyoudo no Zairyoukagaku, (Uchida Rokakuho Pub., Tokyo, 1997) pp. 43-44.

9) K. Maruyama and H. Nakashima: Koonkyoudo no Zairyoukagaku, (Uchida Rokakuho Pub., Tokyo, 1997) pp. 71-117.

10) K. Maruyama and H. Nakashima: Koonkyoudo no Zairyoukagaku, (Uchida Rokakuho Pub., Tokyo, 1997) pp. 197-208. 
11) R. W. Evans and B. Wilshire: Introduction to Creep, (Institute of Materials, London, 1993) pp. 45-66.

12) T. Hasegawa and H. Oikawa: Bulletin Japan Inst. Metals 11 (1972) 192-202.

13) J. C. Giebeling and W. D. Nix: Mater. Sci. Eng. 45 (1980) 123-135.

14) K. R. Williams and R. Wilshire: Met. Sci. J. 7 (1973) 176-179.

15) H. Burt, J. P. Dennison and R. Wilshire: Met. Sci. J. 13 (1979) 295300 .

16) S. Purushothaman and J. K. Tien: Acta Metall. 26 (1978) 519-528.

17) P. Feltham and J. D. Meakin: Acta Metall. 7 (1959) 614-627.

18) J. Rösler and E. Artz: Acta Metal. Mater. 38 (1990) 671-683.

19) L. J. Curry: Metall. Trans. 1 (1970) 395-401.

20) T. Hasegawa, Y. Ikeuchi and S. Kawashima: Met. Sci. J. 6 (1972) 78 82.

21) P. Feltham: Proc. Phys. Soc. B66 (1953) 865-883.

22) J. G. Happer, L. A. Shepard and J. E. Dorn: Acta Metall. 6 (1958) 509518.

23) C. R. Barrett and W. D. Nix: Acta Metall. 13 (1965) 1247-1258.

24) Y. Ishida, C. Chen and J. E. Dorn: Trans. Metall. Soc. AIME 236 (1966) 964-971.

25) A. S. Nowick and E. S. Machlin: J. Appl. Phys. 18 (1947) 79-87.

26) J. J. Jonas: Acta Metall. 17 (1969) 397-405.

27) M. Tamura, H. Esaka and K. Shinozuka: ISIJ Int. 39 (1999) 380-387.

28) M. Tamura, H. Esaka and K. Shinozuka: Mater. Trans., JIM 41 (2000) 272-278.

29) M. Tamura, H. Sakasegawa, Y. Kato, A. Kohyama, H. Esaka and K. Shinozuka: ISIJ Int. 42 (2002) 1444-1451.

30) T. Mura and T. Mori: Maikuromekanikkusu, (Baihu-kan, Tokyo, 1976) pp. 99-108.
31) T. Mura: Micromechanics of Defects in Solids, 2nd ed. (Martinus Nijhoff, 1987) pp. 204-218.

32) National Research Institute for Metals: NRIM Creep Data Sheet, No. 20B (1994) pp. 1-28.

33) F. R. Larson and J. Miller: Trans. ASME 74 (1952) 705-775.

34) H. Kimura: Zairyou-Kyoudo no Kanngae-Kata, (Agune Technical Center, Tokyo, 1998) pp. 379-384.

35) G. Glover and C. M. Sellars: Metall. Trans. 4 (1973) 765-775.

36) R. L. Orr, O. D. Sherby and J. E. Dorn: Trans. ASM 46 (1954) 113-128.

37) National Research Institute for Metals: NRIM Creep Data Sheet, No. 4B (1986) pp. 1-32.

38) R. Tanaka and T. Matsuo: Tetsu-to-Hagane 68 (1982) 226-235.

39) R. Watanabe, Y. Chiba and T. Kuno: Tetsu-to-Hagane 61 (1975) 24052417.

40) Hitachi Metal Ltd. and Nippon Kokan K.K.: A Joint Report on Heat Resistant Alloys for Use in a Steam Generator of Nuclear Steel Making Processes, Vol. 2, (1978) pp. 1-295.

41) M. Tamura, Y. Kamemura, R. Watanabe and Y. Chiba: Tetsu-toHagane 65 (1979) 1022-1030.

42) R. Watanabe and Y. Chiba: Tetsu-to-Hagane 61 (1975) 2274-2294.

43) Japan Institute of Metals: Data Book for Metals, (Maruzen, Tokyo, 1995) pp. 20-25.

44) Iron and Steel Institute of Japan: Tekko-Binran, Vol. 1, (Maruzen, Tokyo, 1981) pp. 343-361.

45) A. Takada, M. Sakane, Y. Tsukada and H. Nishimura: Trans. JSME, A 66 (2000) 589-594.

46) R. J. McCabe and M. E. Fine: JOM 52 (2000, June) 33-35.

47) H. G. Song, J. W. Morris and F. Hua: JOM 54 (2002, June) 30-32.

48) R. W. Evans: Mater. Sci. Tech. 15 (1999) 647-658. 